\title{
COMPARATIVE ASSESSMENT OF INCINERABILITY OF MUNICIPAL SOLID WASTE OVER DIFFERENT ECONOMIES
}

\author{
Roshni Mary Sebastian ${ }^{1, \star}$, Dinesh Kumar ${ }^{2}$ and Babu Alappat ${ }^{1}$ \\ ${ }^{1}$ Department of Civil Engineering, IIT Delhi, Hauz Khas, New Delhi-110016, India \\ ${ }^{2}$ North Delhi Municipal Corporation, New Delhi-110002, India
}

Article Info:
Received:
7 February 2018
Revised:
26 April 2018
Accepted:
22 June 2018
Available online:
30 June 2018
Keywords:
Composite indicator
Incinerability of MSW
Waste to Energy

Article Info:

7 February 2018

22 June 2018

Available online:

30 June 2018

Composite indicator

Waste to Energy

\section{ABSTRACT}

Municipal solid waste (MSW) generation rates have been steadily increasing over the years globally. Simultaneously, the composition of MSW has also been varying. Combined with the scarcity of land for landfilling, waste incineration is now gradually becoming an indispensable part of MSW management, even in developing countries. However, being an economy intensive process, assessment of the feasibility of incineration of MSW becomes vital prior to employing thermal Waste to Energy (WtE) techniques. A composite indicator to easily quantify the incinerability of MSW called incinerability index or $i$ - Index has been developed in this regard. A comparative assessment of incinerability of MSW generated from different economies was drawn using this indicator. It was observed that incinerability of MSW decreased with a decrease in income. However, a marginal increase in incinerability was observed by 2025 in countries belonging to low-income groups.

\section{INTRODUCTION}

MSW management strategies adopted have been evolving over the years, especially in developing countries like India, owing to increasing generation rates, varying composition and growing environmental awareness. Economies that relied largely on composting and landfilling for management of generated MSW is now gradually inclining towards technologies that can handle the quantum of MSW generated at faster rates and occupy lesser space. Consequently, thermal Waste to Energy (WtE) treatment techniques like incineration are gaining prominence as an inalienable element of integrated solid waste management.

Figure 1 formulated using World Bank database demonstrates the disparities in MSW management in countries belonging to different economic groups (Hoornweg and Bhada-Tata, 2012). While open dumping is prevalent in low-income countries, more than $60 \%$ of the generated MSW in high-income countries is diverted from the landfills. With global waste generation stipulated to nearly double to 2.2 billion tonnes per year, it has become quintessential to renounce unsustainable management practices like landfilling with high greenhouse gas (GHG) potential. This has further boosted the growth of the thermal WtE sector, which can also serve as a source of renewable energy. Figure 2(a) developed using USEPA (2014) illustrates a gradual reduction in the quantum of MSW being landfilled, while the quantity of MSW incinerated is nearly constant after a steep increase in the initial stage. Thermal WtE techniques dominate the global WtE market, constituting about $88.2 \%$ of net market revenue (World Energy Council, 2016).

United States (US) and Europe alone have 86 and 455 waste to energy plants, respectively (ISWA, 2012). A significantly steady growth in this sector, however, was observed in China, with almost two-fold growth in WtE capacity in the period from 2010-13, as evident from Figure 2(b) (World Energy Council, 2016). The front-runner in exploiting WtE technology for MSW management is, however, Japan, with incineration of nearly $80 \%$ of the generated MSW (Lombardi et al., 2015). The WtE sector is envisaged to have escalated growth rates in Asia-Pacific region also due to the waste management initiatives in China and India. Attempts to incorporate thermal treatment into integrated waste management had started in the wake of the century in both the countries. However, higher organic fraction and the subsequent high moisture content (MC) and low calorific value tend to reduce the feasibility of WtE treatment. India had its first waste incineration plant set up in 1989, at Timarpur, Delhi. Despite a state of the art design, the plant was shut down after a few weeks of operation due to erroneous assumptions in the thermal characteristics of the MSW feed (Talyan et al., 2004). However, with improving standards of living, waste composition and characteristics have undergone appreciable changes. Singh et al. (2011) also reaffirmed the scope for thermal WtE technologies for MSW management in India. 


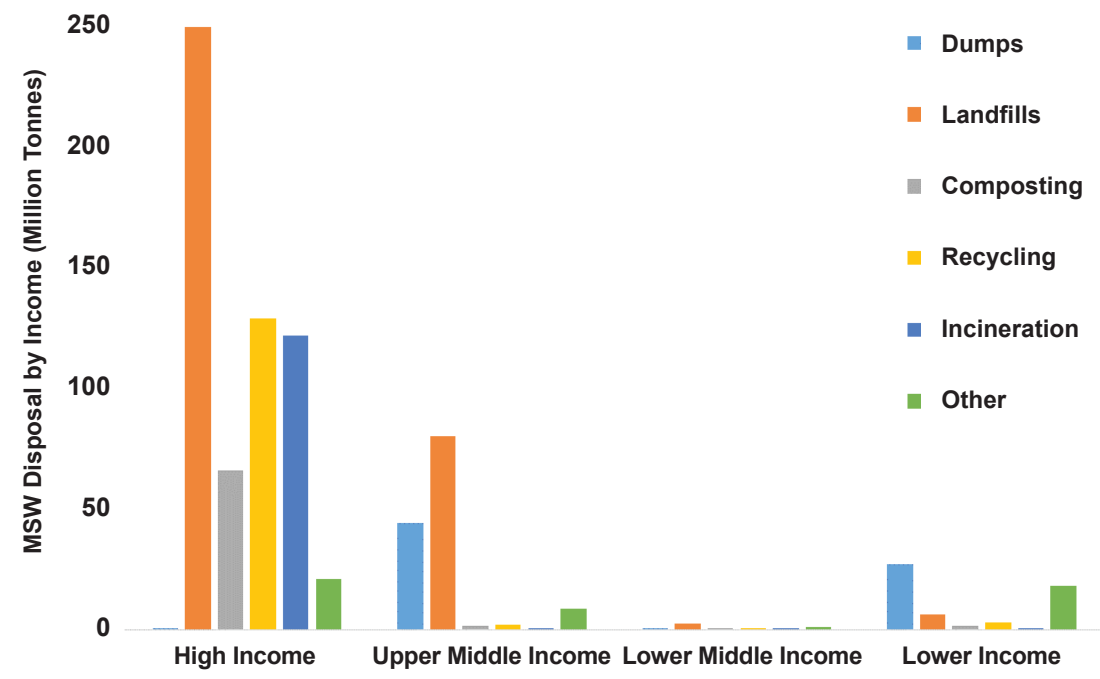

FIGURE 1: MSW disposal techniques adopted in different economies (Data source: Hoornweg and Bhada-tata, 2012).

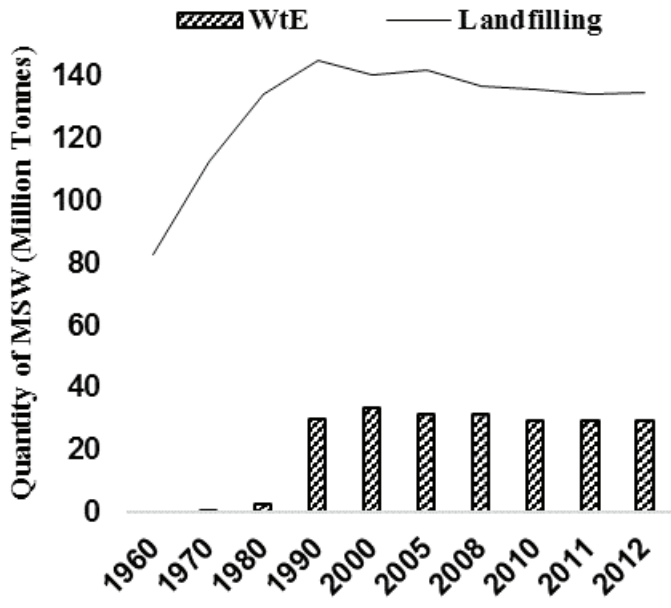

(a) USA

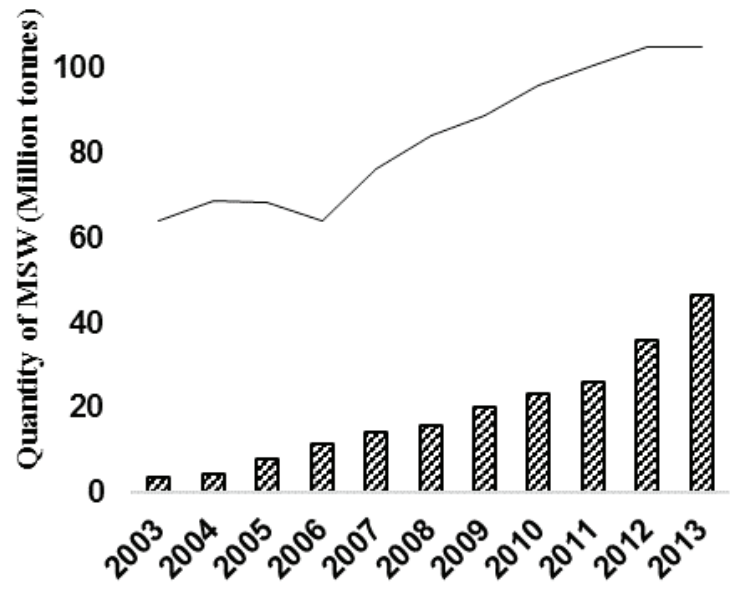

(b) China

FIGURE 2: Quantity of MSW incinerated for energy recovery and disposed of in landfills over the years in the USA and China (Data source: USEPA, 2014; Robinson et al., 2009).

Being a relatively economically exhaustive technology during installation and operation, ensuring the feasibility of incineration of MSW becomes very crucial prior to its execution (Rand et al., 1999). The primary objective of the technology is the disposal of the MSW with minimal load on the environment. Nevertheless, energy recovery is considered an added advantage for the same. Moreover, low calorific values of the generated MSW may necessitate augmenting the feed with an auxiliary fuel which can make the process economically unfeasible.

The feasibility of incineration of MSW, or 'incinerability' of MSW may be defined as the amenability of MSW, to be burned completely to sterile ash, with minimal environmental impact, optimum energy recovery and economic sustainability. The feasibility of the incineration relies on the various properties of the feed to the furnace. While pre-treatment operations can considerably improve its thermal properties, it can prove to be economically exhaustive at the same time. A quick assessment technique for the incinerability of MSW can significantly aid in the de- cision-making process; incorporation of WtE techniques into integrated waste management as well as the need for pre-treatment operations can be determined by employing such a tool. A composite indicator for incinerability (CII) called incinerability index or $i$ - Index of MSW has been developed for the quantification of incinerability of MSW; it encompasses the 3-E criteria which are fundamental for the viability of WtE techniques. $i$ - Index is a novel estimation technique which can ascertain the incinerability of MSW prior to technology selection and framing of integrated waste management strategies.

The paper describes the application of this CII on MSW generated from countries belonging to different income groups. A comparative assessment of incinerability of MSW shall thus be drawn over different economies.

\section{METHODOLOGY FOR THE FORMULATION OF CII: A BRIEF ACCOUNT}

The formulation of the Cll entails four main stages, viz. 
- Selection of parameters that has the potential to affect incinerability of MSW;

- Determination of parameter weightages with reference to incinerability of MSW;

- Development of normalisation curves for rendering the parameters comparable;

- Aggregation of the normalised parameters.

Despite objectivity being a highly desirable factor for assessment of incinerability and subsequent decision-making process, lack of specific data makes the task subjective to some extent. To assuage the associated challenges, opinions of multiple panels of experts have been incorporated in the formulation of the quantification tool (Kumar and Alappat (2003); Saxena and Bhardwaj (2003); Kurian et al. 2005). A list of 13 parameters (Table 1) identified from exhaustive literature surveys was sent to a panel of 138 experts, comprising academicians, consultants, and regulatory authorities. Based on the scoring received on a scale of 1-5 and thorough scrutiny, a revised list of 8 parameters was finalised. The relative weightages of the chosen parameters were established using pairwise comparisons by analytic hierarchy process (AHP) instituted by Saaty (1980). Another expert panel consisting of 201 panellists comprising mostly of academicians and a section of industrial counterparts was approached for the same. 79 individual acceptable responses were acquired at this stage. Further, to transform the parameters to a uniform scale to facilitate their aggregation, graphical normalisation technique was employed. An expert panel comprising of 90 members were approached for developing rating curves for each parameter. An averaged curve was subsequently developed for each parameter based on the feedback from the panellists.

Figure 3 displays the averaged rating curves developed hence. The cumulative impact of these parameters was then estimated by choice of aggregation technique, the values of which can shed light on the incinerability of MSW. Weighted aggregation function was used for deriving CII for MSW

$\mathrm{CII}=\frac{\sum_{1} w_{i} P_{i}}{\sum_{1}^{n} w_{i}}$

where, $w_{i}$ - weightage of each parameter on a scale of $0-1, P_{i}$ - normalised score from rating curves on a scale of $1-100 ; n$ - number of parameters and CII - composite indicator called $i$ - Index on a scale of 0-100.

Being an increasing scale indicator, a higher value sug- gests higher incinerability or better amenability to incineration. A step-by-step account of the formulation of $i$ - Index has been presented by Sebastian et al. (2018). A comparison of the incinerability of MSW generated from countries belonging to different income groups, namely, high-income countries (HIC), upper-middle-income countries (UMIC), lower-middle-income countries (LMIC) and low-income countries (LIC), shall be drawn using CII.

\subsection{Characteristics of the MSW generated from study areas}

The composition of MSW generated in the afore-mentioned regions, reported by Hoornweg and Bhada-tata (2012), was used for the study. The same has also been illustrated in Figure 4. While organic fraction constituted more than $50 \%$ of the generated MSW in countries belonging to lower income groups, combustible components like paper and plastic formed a major fraction of MSW generated in HIC. Hence, the calorific value of the MSW in the former was considerably lower in comparison to the latter. The composition of the MSW influences the thermal characteristics and consequently the feasibility of incineration for energy recovery. This could also affect the auxiliary fuel requirement when the MSW is subjected to incineration. Furthermore, the pollution potential of MSW incineration also needs to be considered while estimating the incinerability of MSW. The various parameters for computation of CII were theoretically computed by the approach proposed by Kaiser (1966).

In order to estimate the incinerability of the MSW generated from study areas, the theoretically estimated input parameters were normalised using Figure 3. With the relative weightages and the normalised values known, the CII was computed subsequently by equation (1).

\section{RESULTS AND DISCUSSION}

The results of the assessment of incinerability of raw MSW over different economies have been tabulated in Table 2 . Table 3 displays the values for the same projected to 2025.

The CII of raw MSW from HIC was found to be nearly $30 \%$ higher than that of LIC. Higher organic fraction and the consequent moisture content may have caused considerably low incinerability for MSW generated in LIC. Moreover, the $\mathrm{SO}_{2}$ release potential was found to be appreciably higher for the MSW generated in LIC, in comparison to

TABLE 1: List of parameters sent to the panel of experts in the preliminary survey.

\begin{tabular}{|c|c|c|}
\hline$\%$ Moisture content & $\%$ Inert content & $\begin{array}{l}\text { Greenhouse gases (GHG) } \\
\text { released/kg MSW feed }\end{array}$ \\
\hline Heat content/kg of MSW feed & $\begin{array}{l}\text { Total primary pollutants } \\
\text { released/kg of MSW feed }\end{array}$ & $\begin{array}{l}\text { Quantity of auxiliary fuel required per kg } \\
\text { of MSW feed to maintain a particular } \\
\text { temperature, say } 10000 \mathrm{C}\end{array}$ \\
\hline$\%$ Volatile content & $\begin{array}{l}\text { Stoichiometric air required for } \\
\text { incinerating } / \mathrm{kg} \text { of MSW feed }\end{array}$ & Bulk Density of MSW feed \\
\hline $\begin{array}{l}\text { Ultimate analysis } \\
\text { of MSW feed }\end{array}$ & Specific heat & $\begin{array}{l}\text { Size of the MSW feed } \\
\text { used for energy recovery }\end{array}$ \\
\hline $\begin{array}{l}\text { Time required for complete } \\
\text { combustion of } 1 \mathrm{~kg} \mathrm{MSW} \mathrm{feed}\end{array}$ & & \\
\hline
\end{tabular}




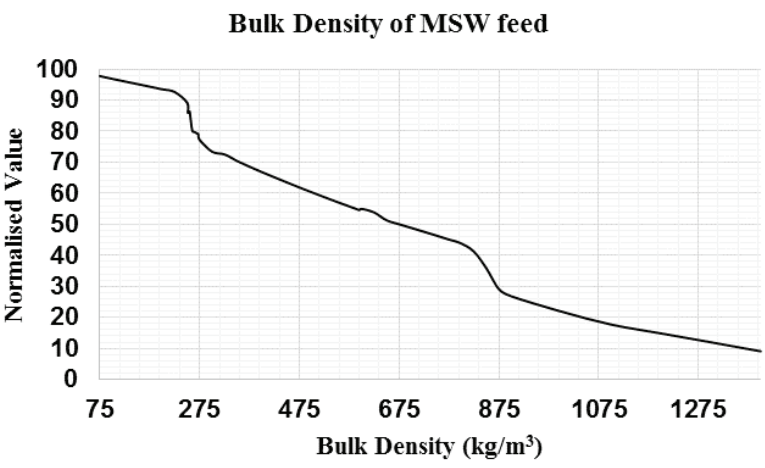

Calorific Value of MSW feed

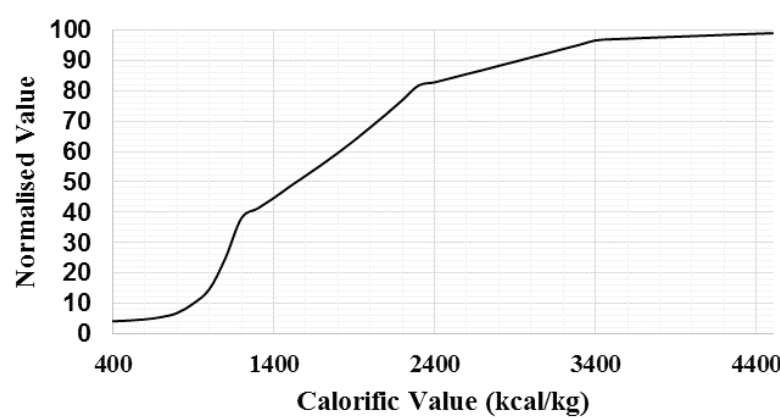

$\mathrm{CO}_{2}$ Released from MSW feed

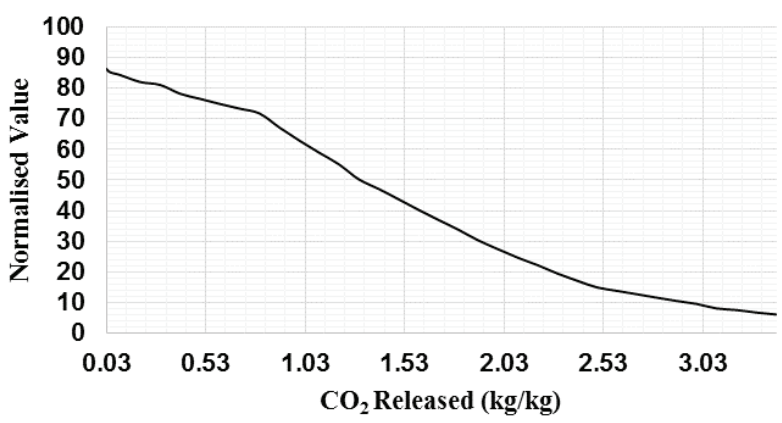

Auxiliary Fuel Requirement

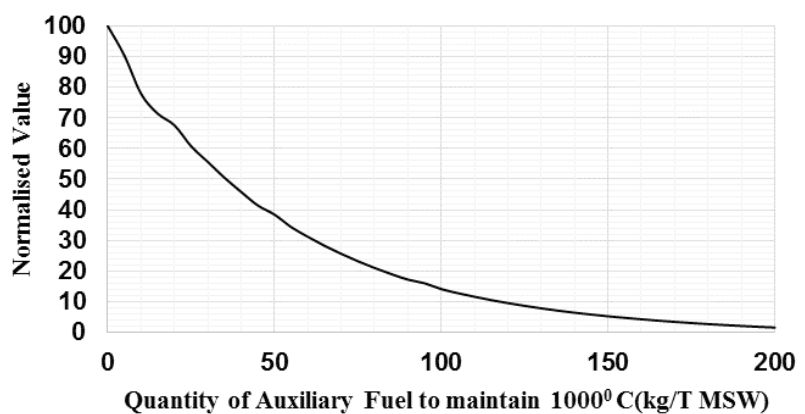

FIGURE 3 [ i ] : Normalisation curves for (a) Bulk density (b) $\mathrm{CO}_{2}$ released (c) Calorific value (d) Auxiliary fuel requirement.

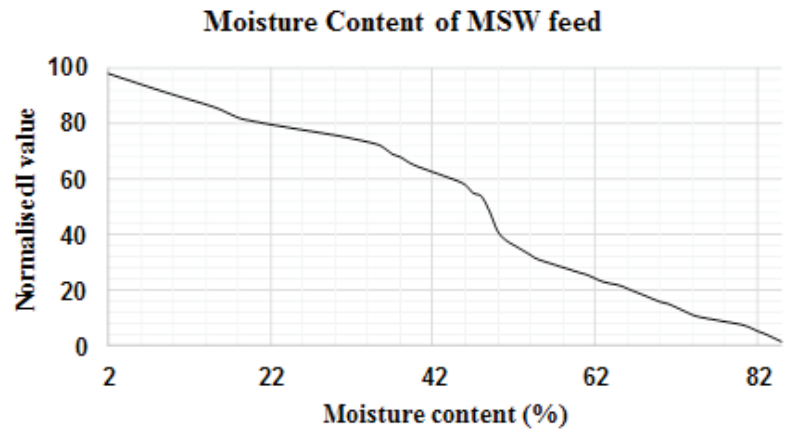

$\mathrm{SO}_{2}$ Released from MSW feed

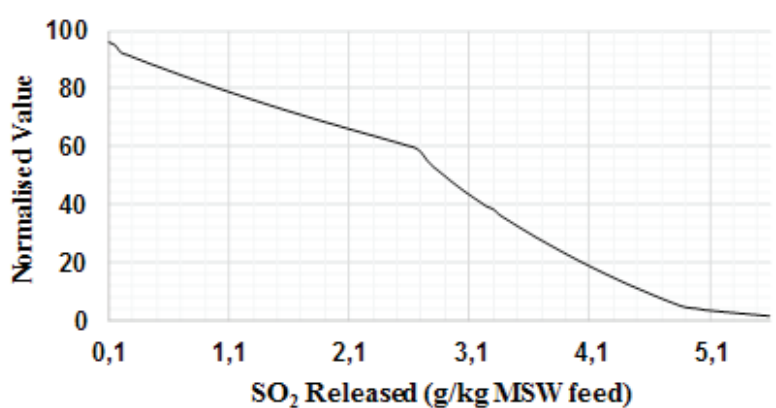

Specific Heat of MSW feed

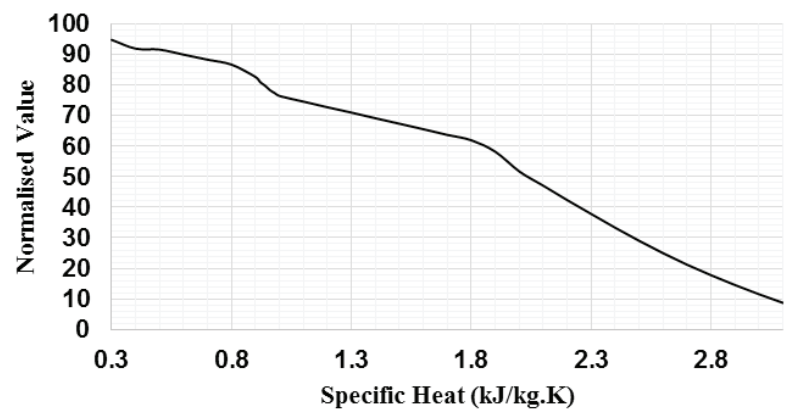

Volatile Content of MSW feed

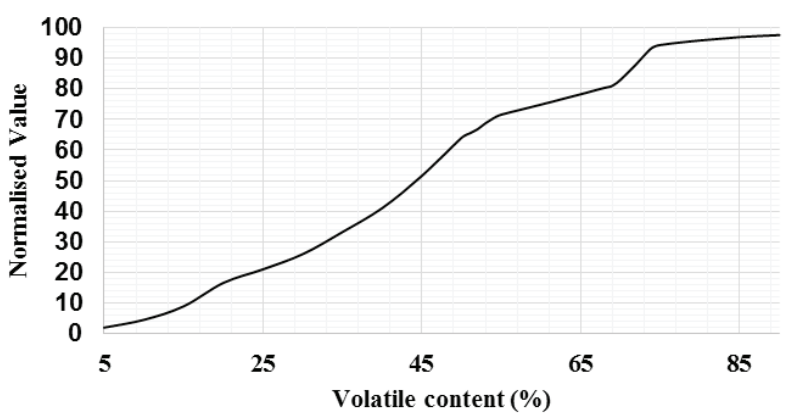

FIGURE 3 [ ii ]: Normalisation curves for (e) Moisture content (f) Specific heat (g) $\mathrm{SO}_{2}$ released (h) Volatile content.

HIC. Within MIC, the biodegradable fraction is $8.47 \%$ higher in LMIC, in contrast to UMIC. Since this can increase the sulphur content in the MSW, the $\mathrm{SO}_{2}$ release potential was higher in LMIC as well, relative to MSW generated in LMIC. Subsequently, the CII of raw MSW in UMIC was found to be
7.5\% higher than LMIC. The composition of MSW generated in a particular region is affected by economic growth, standards of living, and cultural and climatic variations. This was further reflected in the incinerability of the generated MSW. 


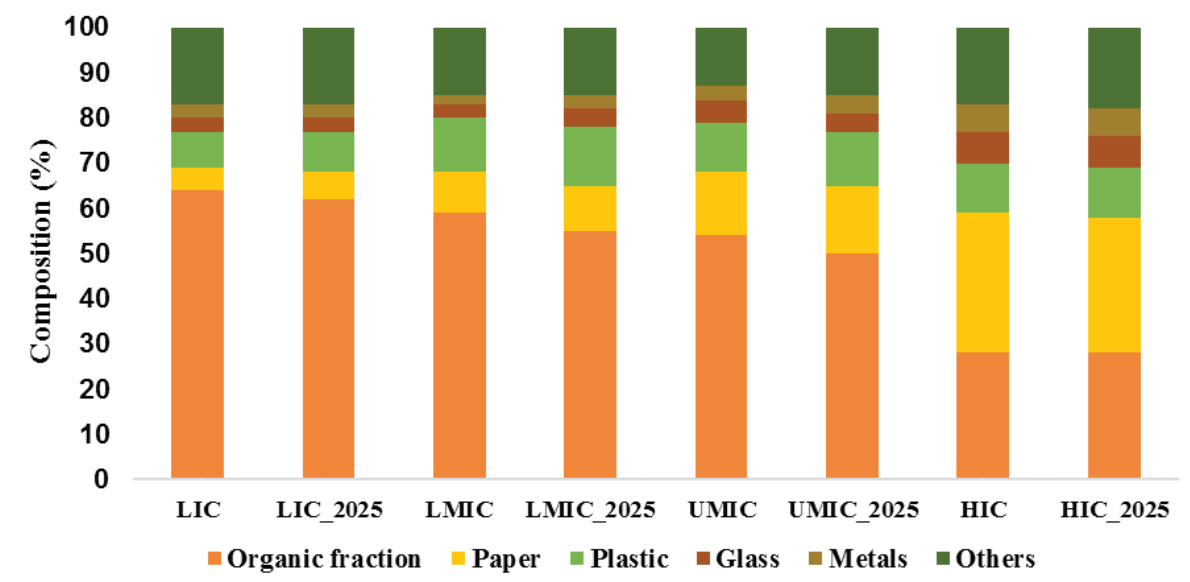

FIGURE 4: Percentage composition of MSW in different economies presently and projected to 2025 . All the values are expressed in wet weight basis (Data source: Hoornweg and Bhada-tata, 2012).

An attempt to estimate the incinerability of MSW over different economies by 2025 was also carried out. While the incinerability of MSW improved marginally in LIC and MIC, a negligible drop in incinerability was observed in the MSW generated from HIC. Minor reduction in the paper waste generation in $\mathrm{HIC}$ may have triggered this trend in the latter. Ranking of the MSW generated in countries belonging to different income groups for the current year and projected values for 2025 is illustrated in Figure 5. The variation in the values of the indicator also suggests that a higher value of Cll, towards 100 indicates an MSW of higher incinerability. Such MSW samples when fed to the furnace can be incinerated with energy recovery and minimal environmental impact, without being economically exhaustive. On the other hand, a lower value of CII hints at the unfeasibility of incineration. The indicator was also computed for refuse-derived fuel (RDF) which has a high heat content of about $4774 \mathrm{kcal} / \mathrm{kg}$. While the MSW generated in $\mathrm{HIC}$ had the CIl relatively closer to RDF, implying very high incinerability, the MSW generated in countries belonging to lower economic groups had significantly lower incinerability rating. Further, the flue gas released from incineration of RDF has been reported to have relatively lower pollution potential, which is evident from the incinerability rating. The flue gas generated from incineration of MSW generated in HIC was also observed to have lower pollution potential, in comparison to MSW generated in other economies. The parameter scores for $\mathrm{SO}_{2}$ released substantiates this. The CIl thus conveys the incinerability of MSW, while incorporating the 3-E concept, based on which decision-making can be accomplished.

Apart from ranking the generated MSW, the CII can also be used as a decision-making tool for the implementation of WtE techniques for MSW management. Based on the quantified incinerability, need for the pre-treatment can be identified. For instance, although the Cll value for MSW from LIC is comparatively low, drying can considerably improve its thermal properties and hence the amenability to incineration. The choice of the pre-treatment techniques may be made using individual incinerability rating of the parameters under consideration. For instance, the individ- ual incinerability score for bulk density of MSW generated in LIC was 55, as opposed to an appreciably high score of 96.3 for MSW generated in HIC. Pre-treatment operations that entail the removal of inert and other bulky constituents of MSW shall help improve the overall incinerability of MSW. Moreover, seasonal and annual fluctuations of the MSW generated in a particular locality may be computed to ascertain the incinerability of MSW, prior to adopting incineration for waste management. This data can help foresee the incinerability of MSW into future years, which can avert the closure of the plant due to poor thermal characteristics of the MSW feed.

\section{CONCLUSIONS}

With WtE techniques gradually becoming a significant element of integrated waste management, studies on the feasibility of incineration have become inevitable. For easy quantification of amenability to incineration of MSW, a composite indicator for incinerability called $i$ Index has been developed. Using the incinerability thus quantified, a ranking of MSW on the basis of its feasibility for incineration can be derived. MSW generated from different economies were used to demonstrate the application of this composite indicator. While MSW generated from HIC had high $i$ - Index values of 73 that generated from LIC displayed a low $i$ - Index value of 51.5. Consequently, MSW generated from LIC was deduced to be less amenable to incineration. Further, the incinerability of MSW was estimated to improve by at least $1-1.5 \%$ by 2025 in LIC and MIC, due to improving standards of living in those countries, which reflected in the composition of the generated MSW. However, a negligible decrease is anticipated in the incinerability of MSW generated from HIC by 2025 . This was due to the marginal decrease in the paper fraction in the generated MSW. In addition to establishing the feasibility of incineration, this composite indicator may also be used for estimating the pre-treatment operations required to improve the incinerability of MSW. Being an economy-intensive technology, feasibility studies are crucial prior to its implementation. A tool like $i$ - Index which can help promptly analyse the incinerability 
TABLE 2: Incinerability assessment of MSW from different economies for 2012.

\begin{tabular}{|c|c|c|c|c|c|c|c|c|c|c|c|c|c|}
\hline 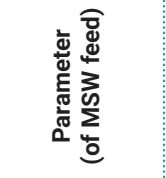 & 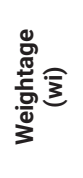 & 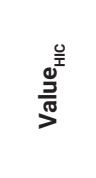 & 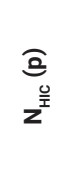 & 总 & 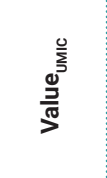 & 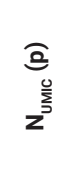 & 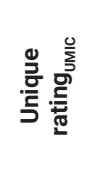 & 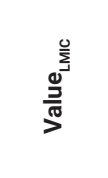 & 仝 & 兽总 & $\frac{\stackrel{0}{\frac{0}{J}}}{\frac{0}{50}}$ & $\overbrace{0}^{\underline{0}}$ & 竞 施 \\
\hline $\begin{array}{c}\text { Bulk Density } \\
\left(\mathrm{kg} / \mathrm{m}^{3}\right)\end{array}$ & 0.092 & 125 & 96.3 & 9.897 & 250 & 90 & 9.250 & 500 & 60.6 & 6.228 & 600 & 55.5 & 5.704 \\
\hline $\begin{array}{c}\mathrm{CO}_{2} \text { Released } \\
(\mathrm{kg} / \mathrm{kg} \mathrm{MSW} \\
\text { feed })\end{array}$ & 0.148 & 1.092 & 88.5 & 12.547 & 1.019 & 90 & 12.760 & 1.024 & 90.4 & 12.817 & 0.941 & 91.4 & 12.958 \\
\hline $\begin{array}{l}\text { Heat content } \\
(\mathrm{kcal} / \mathrm{kg})\end{array}$ & 0.152 & 2467.5 & 93.5 & 15.026 & 2189.7 & 76 & 12.214 & 2166.06 & 75.5 & 12.134 & 1791.2 & 59.8 & 9.610 \\
\hline $\begin{array}{c}\text { Moisture } \\
\text { content (\%) }\end{array}$ & 0.09 & 18.81 & 81.8 & 7.893 & 30.67 & 75.9 & 7.324 & 33.02 & 75 & 7.237 & 35.41 & 73.4 & 7.083 \\
\hline $\begin{array}{c}\text { Auxiliary } \\
\text { Fuel required } \\
\text { to maintain } \\
10000 \mathrm{C} \\
\text { (kg/T MSW } \\
\text { feed) }\end{array}$ & 0.134 & 0 & 99.9 & 13.4 & 31.5 & 53.1 & 7.13 & 40.86 & 42.8 & 5.74 & 71.75 & 22 & 2.95 \\
\hline $\begin{array}{c}\mathrm{SO}_{2} \text { Released } \\
(\mathrm{g} / \mathrm{kg} \mathrm{MSW} \\
\text { feed) }\end{array}$ & 0.161 & 2.854 & 52 & 7.477 & 3.072 & 45.6 & 6.557 & 3.152 & 42.7 & 6.140 & 3.269 & 39.6 & 5.694 \\
\hline Specific Heat & 0.097 & 1.961 & 53.2 & 5.446 & 2.545 & 28.3 & 2.897 & 2.659 & 22.2 & 2.272 & 2.747 & 19.1 & 1.955 \\
\hline $\begin{array}{c}\text { Volatile } \\
\text { content }(\%)\end{array}$ & 0.124 & 55.10 & 72 & 9.452 & 50.62 & 64.6 & 8.481 & 49.88 & 63.9 & 8.389 & 45.85 & 53.8 & 7.063 \\
\hline Cll or $i^{-}$Index & & & & 73.31 & & & 61.56 & & & 59.24 & & & 51.55 \\
\hline
\end{tabular}

TABLE 3: Incinerability assessment of MSW from different economies projected to 2025.

\begin{tabular}{|c|c|c|c|c|c|c|c|c|c|c|c|c|c|}
\hline 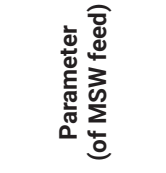 & 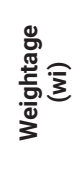 & 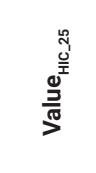 & 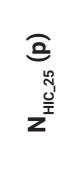 & Ð & 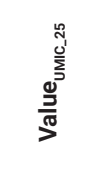 & 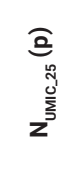 & 怘 & 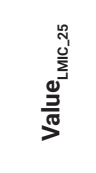 & 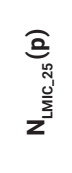 & ᄂั & 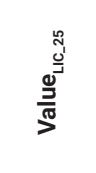 & 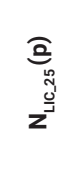 & 苟 \\
\hline $\begin{array}{c}\text { Bulk Density } \\
\left(\mathrm{kg} / \mathrm{m}^{3}\right)\end{array}$ & 0.092 & 319.8 & 72.3 & 6.69 & 277.6 & 76.5 & 7.08 & 273.1 & 78.3 & 7.25 & 286.4 & 74.6 & 6.91 \\
\hline $\begin{array}{c}\mathrm{CO}_{2} \text { Released } \\
(\mathbf{k g} / \mathbf{k g ~ M S W} \\
\text { feed })\end{array}$ & 0.148 & 0.8 & 71.9 & 10.67 & 0.8 & 72.2 & 10.72 & 0.7 & 72.3 & 10.74 & 0.7 & 73.3 & 10.89 \\
\hline $\begin{array}{l}\text { Heat content } \\
(\mathrm{kcal} / \mathrm{kg})\end{array}$ & 0.152 & 2436.9 & 82.5 & 12.57 & 2259.4 & 79.2 & 12.07 & 2225.4 & 78.3 & 11.93 & 1877.4 & 63.2 & 9.63 \\
\hline $\begin{array}{c}\text { Moisture } \\
\text { content (\%) }\end{array}$ & 0.09 & 18.8 & 81.2 & 7.28 & 28.9 & 76.2 & 6.83 & 31.1 & 74.7 & 6.69 & 34.5 & 72.8 & 6.52 \\
\hline $\begin{array}{c}\text { Auxiliary } \\
\text { Fuel required } \\
\text { to maintain } \\
10000 \mathrm{C} \\
\text { (kg/T MSW } \\
\text { feed) }\end{array}$ & 0.134 & 0 & 99.9 & 13.42 & 26 & 60.2 & 8.08 & 31.6 & 53.1 & 7.13 & 64.3 & 28.6 & 3.84 \\
\hline $\begin{array}{c}\mathrm{SO}_{2} \text { Released } \\
\text { (g/kg MSW } \\
\text { feed) }\end{array}$ & 0.161 & 2.9 & 51.5 & 8.32 & 3 & 46.1 & 7.45 & 3 & 46.1 & 7.45 & 3.2 & 40.4 & 6.52 \\
\hline $\begin{array}{c}\text { Specific } \\
\text { Heat }\end{array}$ & 0.097 & 2 & 54.6 & 5.27 & 2.5 & 31.6 & 3.05 & 2.6 & 26.4 & 2.55 & 2.7 & 21.2 & 2.05 \\
\hline $\begin{array}{l}\text { Volatile } \\
\text { content (\%) }\end{array}$ & 0.124 & 54.5 & 70.8 & 8.82 & 51.2 & 65.7 & 8.18 & 49.9 & 64 & 7.97 & 46.7 & 54.4 & 6.78 \\
\hline $\begin{array}{c}\text { Cll or } \\
i \text { - Index }\end{array}$ & & & & 73.04 & & & 63.46 & & & 61.71 & & & 53.13 \\
\hline \multicolumn{14}{|c|}{ 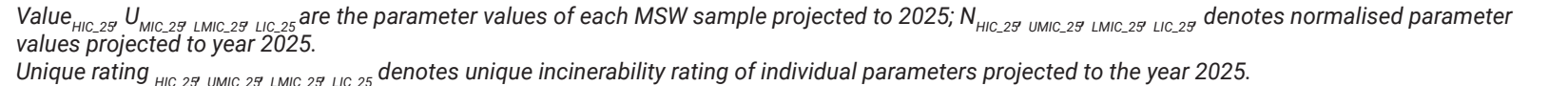 } \\
\hline
\end{tabular}


of MSW shall be instrumental in framing MSW management strategies.

\section{ACKNOWLEDGMENTS}

The authors would like to thank the panelists for their prompt and valuable responses throughout the course of the work.

\section{REFERENCES}

Hoornweg, D. and Bhada- Tata, P. (2012). What a Waste: A Global Review of Solid Waste Management, n. 15.

ISWA. (2013). ISWA Guidelines: Waste to Energy in Low and Middle-Income Countries, 1-29.

Kaiser, E.R. (1966). Chemical Analyses of Refuse Components, Department of Chemical Engineering, New York University, New York.

Kumar, D. and Alappat, B.J. (2003). A technique to quantify landfill leachate pollution. In: CISA (eds.): Ninth International Landfill Symposium, 3-7 October 2003, Cagliari, Italy, paper n. 400, 241-242. CISA, St Margherita di Pula, Cagliari, Italy.

Kurian, J., Esakku, S., Nagendran, R. and Viswanathan. (2005). A Decision-Making Tool for Dumpsite Rehabilitation in Developing Countries, Proceedings Sardinia 2005, Tenth International Waste Management and Landfill Symposium, Sardinia.

Ministry of Urban Development. (2014). Municipal Solid Waste Management on a Regional Basis, Government of India.

National Bureau of Statistics of China. (2014). China Statistical Yearbook, China Statistics Press: Beijing, China.

Rand, T., Haukohl, J. and Marxen, U. (1999). Municipal solid waste incineration, Technical Guidance Report, The World Bank, Washington DC.
Robinson, A. Swell, G. c. Wu, S., Damodaran, N. and Kalas- Adams N. (2009). Landfill Data from China: Addressing Information Needs for Methane Recovery. In: Proceedings of the 2nd Coal Ned Methane World Conference, 10-11 March 2009, Jakarta, Indonesia.

Saaty, T. L. (1977). A scaling method for priorities in hierarchical structures, Journal of Mathematical Psychology. vol. 15, n. 3, 234-281.

Saxena, A.K. and Bhardwaj, K.D. (2003) Environmental Assessment and up-gradation plan for existing municipal waste disposal site - A case study. Proc. Workshop on Sustainable Landfill Management, Chennai, India, 287 - 301.

Sebastian R.M., Kumar D. And Alappat B. J., 2018. A Technique to Quantify Incinerability of Municipal Solid Waste. Waste Management and Research. (Under review).

Sebastian R.M., Kumar D. and Alappat B. J. , 2017. Comparative Assessment of Incinerability of Municipal Solid Waste over Different Economies. Proc. Sardinia. 15th Int. Waste Manag. Landfill Symp. Cagliari, Italy.

Sharholy, M., Ahmad, K., Mahmood G. and Trivedi R.C. (2008) Municipal Solid Waste Management in Indian Cities - A Review, Waste Management, vol. 28, 459-167.

Singh, R. P., Tyagi, V. V., Allen T., Ibrahim M. H. and Kothari R. (2011). An Overview for Exploring the Possibilities of Energy Generation from Municipal Solid Waste (MSW) in Indian Scenario, Renewable and Sustainable Energy Reviews, vol. 15, n. 9, 4797- 4808.

Talyan, V., Dahiya, R.P. and Sreekrishnan, T.R. (2008). State of Municipal Solid Waste Management in Delhi, the Capital of India. Waste Management, vol. 28, .1276-1287.

USEPA. (2014). Municipal Solid Waste Generation recycling and Disposal Tables and Figures for 2012. U.S. Environmental Protection Agency Office of Resource Conservation and Recovery.

World Energy Council. (2016). World Energy Resource: Waste to Energy 2016, 1-74. 